CLINICAL STUDY

\title{
Body composition and metabolic parameters are associated with variation in thyroid hormone levels among euthyroid young men
}

\author{
Greet Roef, Bruno Lapauw, Stefan Goemaere, Hans-Georg Zmierczak, Kaatje Toye, Jean-Marc Kaufman \\ and Youri Taes \\ Department of Endocrinology and Metabolic Bone Diseases, Ghent University Hospital, De Pintelaan 185, 9000 Ghent, Belgium \\ (Correspondence should be addressed to G Roef; Email: greet.roef@ugent.be)
}

\begin{abstract}
Objective: Thyroid disorders affect metabolism and body composition. Existing literature has been conflicting on whether this is also the case for thyroid hormone levels within the euthyroid range. Therefore, we have investigated the relationship between thyroid hormone concentrations and body composition together with metabolic parameters in a population of healthy euthyroid men.

Methods: Healthy male siblings ( $n=941,25-45$ years, median BMI 24.6) were recruited in a cross-sectional, population-based study; a history or treatment of thyroid disease and thyroid autoimmunity were exclusion criteria. Body composition and muscle cross-sectional area were assessed by dual-energy X-ray absorptiometry and peripheral quantitative computed tomography. Total (triiodothyronine $\left(\mathrm{T}_{3} ; \mathrm{TT}_{3}\right)$ thyroxine and $\left(\mathrm{T}_{4} ; \mathrm{TT}_{4}\right)$ ) and free thyroid hormones $\left(\mathrm{FT}_{3}\right.$ and $\left.\mathrm{FT}_{4}\right)$, $\mathrm{TSH}$, and reverse $\mathrm{T}_{3}\left(\mathrm{rT}_{3}\right)$ and thyroid-binding globulin (TBG) were determined using immunoassays. Results: BMI was positively associated with $(\mathrm{F}) \mathrm{T}_{3}(P<0.0001)$. Whole body fat mass displayed positive associations with $\mathrm{TT}_{3}$ and with $(\mathrm{F}) \mathrm{T}_{4}$ and TBG $(P \leq 0.0006)$. Positive associations were further observed between leptin and $(\mathrm{F}) \mathrm{T}_{3}, \mathrm{TT}_{4}$, and $\mathrm{TBG}(P \leq 0.0002)$. Inverse associations between lean mass and muscle cross-sectional area and $(\mathrm{F}) \mathrm{T}_{3},(\mathrm{~F}) \mathrm{T}_{4}$, and TBG were observed $(P \leq 0.0003)$. Higher levels of $(\mathrm{F}) \mathrm{T}_{3}$ and $\mathrm{TBG}$ were associated with lower insulin sensitivity, assessed by homeostatic model assessment of insulin resistance (IR; $P \leq 0.0001$ ). No associations between TSH and body composition or metabolic parameters were seen.

Conclusion: We show that a less favorable body composition (with higher fat and lower muscle mass and accompanying higher leptin concentrations) and IR are associated with higher thyroid hormone levels in healthy young men with well characterized euthyroidism.
\end{abstract}

European Journal of Endocrinology 167 719-726

\section{Introduction}

Thyroid hormones are important regulators of basal and total energy consumption and can therefore influence body composition (1). Indeed, thyroid dysfunction has profound effects on body composition, as thyrotoxicosis is associated with weight loss and hypothyroidism appears to cause a modest increase in weight $(2,3)$. Recently, there has been growing interest in the potential impact of differences in thyroid function within the normal range on weight and other parameters of body composition $(4,5,6,7,8)$. Positive associations between TSH serum levels and BMI have been reported $(5,7,8,9)$, but these associations remain unconfirmed $(10,11,12)$ and most studies provide information only on BMI. However, BMI does not provide detailed information on body composition as it does not differentiate between lean and fat mass or regional fat distribution.

Conversely, the effects of weight status on circulating thyroid hormones have also been studied. Increases in
TSH and (free)triiodothyronine $\left(\mathrm{T}_{3}\right)$ in obesity (13) or an increase in TSH in individuals subject to weight gain during the course of years were found (14). These alterations in thyroid hormone concentrations in obesity could be an adaptive process in response to the increased body weight (13). Adipocytokines such as leptin might play a role in the interrelation between thyroid hormone levels and body composition (15), as leptin was shown to upregulate TRH expression in the hypothalamus (16).

Furthermore, both hyper- and hypothyroidism have been reported to be associated with insulin resistance (IR) (17). Moreover, administration of $\mathrm{T}_{3}$ to normal volunteers results in IR (18). However, little is known about the influence of variation in thyroid hormone levels on insulin sensitivity in euthyroid persons.

Besides weight loss and IR, muscular wasting is another common and well-known consequence of thyrotoxicosis (19), although the mechanisms underlying this effect are incompletely understood. Reduced muscle cross-sectional area was observed in subclinical 
hyperthyroidism (20), whereas elderly men with the lowest $\mathrm{T}_{3}$ levels were reported to have the highest lean body mass (21).

The aim of this study was to assess the associations of indices of thyroid function with body composition and metabolic parameters in a population of young, healthy, euthyroid men, guided by previously observed effects of thyroid hormone levels within the normal range on bone characteristics in our and other cohorts $(22,23)$.

\section{Materials and methods}

\section{Study design and population}

This study is part of a larger study, in which the determinants of body composition and bone mass in young men are investigated. Participants were recruited from the population registries of the semirural to suburban communities around Ghent, Belgium. Inclusion criteria and study design were described previously $(24,25)$. Men aged 25-45 years old were contacted by direct mailing, briefly describing the study purpose and were asked if they had a brother within the same age range also willing to participate. Finally, a sample of 1114 men agreed to participate. After exclusions, 1001 men were included in the study: 435 brother pairs, 25 families with three brothers and two families with four brothers. Ninety-two men were included as single participants, when their brother could not participate in the study. All analyses were done taking into account the family structure. The maximal age difference within brother pairs was arbitrarily set at 12 years. All participants were in good health and completed questionnaires about previous illness and medication use. Exclusion criteria were defined as illnesses or medication use affecting body composition, hormone, or bone metabolism: current or prolonged ( $>3$ months) use of glucocorticosteroids, anti-androgens, vitamin D supplements, insulin, thyroxine $\left(\mathrm{T}_{4}\right)$, previous or current use of anti-epileptic drugs, hypogonadism, hyperthyroidism, cystic fibrosis, malabsorption or eating disorders, disorders of collagen metabolism or bone development, chronic renal failure, alcohol abuse, and autoimmune rheumatoid disease. All subjects were tested for the presence of thyroid autoantibodies, and those with serum levels above the clinical cutoff (thyroperoxidase antibody (TPOAb) >35 U/l or thyroglobulin antibody $(\mathrm{TgAb})>115 \mathrm{U} / \mathrm{l})$ were additionally excluded (60 persons or $5.3 \%$ of our population), leaving 941 subjects. The study protocol was approved by the ethical committee of the Ghent University Hospital and written informed consent was obtained from all participants. Smoking habits were registered as current or previous smoking.

\section{Body composition}

Body weight was measured in light indoor clothing without shoes. Standing height was measured using a wall-mounted Harpenden stadiometer (Holtain Ltd., Crymuch, UK). Body composition (whole body lean mass and fat mass, trunk fat mass) was determined using dual-energy X-ray absorptiometry (QDR-4500 A, software version 11.2.1; Hologic, Inc., Bedford, MA, USA). Cross-sectional muscle area at dominant forearm and lower leg (66\% from distal end) was determined using a peripheral quantitative computed tomography device (XCT-2000, Stratec Medizintechnik, Pforzheim, Germany).

\section{Biochemical determinations}

Venous blood samples were obtained between 0800 and $1000 \mathrm{~h}$ after overnight fasting. All serum samples were stored at $-80{ }^{\circ} \mathrm{C}$ until batch analysis. Thyroid tests included TSH, free $\mathrm{T}_{4}\left(\mathrm{FT}_{4}\right)$, free $\mathrm{T}_{3}\left(\mathrm{FT}_{3}\right)$, total $\mathrm{T}_{3}\left(\mathrm{TT}_{3}\right)$, total $\mathrm{T}_{4}\left(\mathrm{TT}_{4}\right)$, reverse $\mathrm{T}_{3}\left(\mathrm{rT}_{3}\right)$, and thyroid-binding globulin (TBG) as well as TPOAbs and TgAbs. $\mathrm{rT}_{3}$ and TBG were measured using a RIA (DIAsource ImmunoAssays S.A., Nivelles, Belgium). All other thyroid tests were performed using immunoelectrochemiluminescence (Roche reagents) on Modular E or Cobas 411 (Roche Diagnostics GmbH). Other commercial immunoassays were used to measure serum concentrations of insulin (Roche Diagnostics $\mathrm{GmbH}$ ) and leptin (Linco Research, Inc., St Louis, MO, USA). In a subgroup of 722 subjects, commercial immunoassays were used to determine serum levels of total testosterone, sex hormone-binding globulin (SHBG; Orion Diagnostica, Espoo, Finland), estradiol ( $\mathrm{E}_{2}$; Clinical Assay; DiaSorin, Saluggia, Italy), insulin-like growth factor 1 (IGF1), and IGFBP3 (Diagnostic Laboratory Systems, Inc., Webster, TX, USA).

The intra- and interassay coefficients of variation (\%) were below $10 \%$ for all measurements. Homeostatic model assessment of IR (HOMA-IR) was calculated as follows: (fasting insulin $(\mathrm{U} / \mathrm{l}) \times$ fasting glucose $(\mathrm{mg} / \mathrm{dl})) / 405$, as described by Matthews et al. (26).

\section{Statistical analysis}

Descriptives are expressed as mean \pm s.D. or median (first to third quartile) when criteria for normality were not fulfilled (Kolmogorov-Smirnov) and variables (hormone concentrations, parameters of body composition, and muscle force) were log-transformed in subsequent linear models. Linear mixed-effects modeling with random intercepts and a simple residual correlation structure for random effects were used to evaluate cross-sectional relationships in our study population, taking the interdependence of measurements within families into account. Parameters of fixed effects were estimated via restricted maximum likelihood estimation and reported 
Table 1 General characteristics, body composition, and thyroid hormone concentrations of all study participants $(n=941)$. Total population consisted of 1001 subjects. Subjects with positive thyroid autoimmunity were excluded (60 subjects or $5 \%$ ), leaving 941 subjects. Variables are given as mean \pm s.D.; when there was a non-Gaussian distribution, data were presented as median (first to third quartile). Conversion factor for $\mathrm{FT}_{3}$ from $\mathrm{pg} / \mathrm{dl}$ to $\mathrm{pmol} / \mathrm{l}$, for $\mathrm{TT}_{3}$ from $\mathrm{ng} / \mathrm{dl}$ to $\mathrm{nmol} / \mathrm{l}$, and for $\mathrm{rT}_{3}$ from $\mathrm{ng} / \mathrm{dl}$ to $\mathrm{nmol} / \mathrm{l}$ is 0.0154 conversion factor for $\mathrm{FT}_{4}$ from $\mathrm{ng} / \mathrm{dl}$ to $\mathrm{pmol} / \mathrm{l}$ and for $\mathrm{TT}_{4}$ from $\mu \mathrm{g} / \mathrm{dl}$ to $\mathrm{nmol} / \mathrm{l}$ is 12.87; conversion factor for TBG from $\mathrm{mg} / \mathrm{dl}$ to $\mathrm{mg} / \mathrm{l}$ is 0.1 .

\begin{tabular}{|c|c|c|}
\hline Parameter & $\begin{array}{c}\text { Mean } \pm \text { s.D. } \\
\text { Median IQ (25th-75th) }\end{array}$ & $\begin{array}{l}\text { Reference } \\
\text { range }\end{array}$ \\
\hline \multicolumn{3}{|l|}{ General characteristics } \\
\hline Age (years) & $34(30-39)$ & \\
\hline Height $(\mathrm{cm})$ & $179.6 \pm 6.5$ & \\
\hline Weight (kg) & $79(73-87.5)$ & \\
\hline BMI $\left(\mathrm{kg} / \mathrm{m}^{2}\right)$ & $24.6(22.7-26.9)$ & \\
\hline Smokers (\%) & 24 & \\
\hline \multicolumn{3}{|l|}{ Body composition } \\
\hline $\begin{array}{l}\text { Whole body total } \\
\text { fat mass }(\mathrm{kg})\end{array}$ & $15.4(11.5-19.7)$ & \\
\hline $\begin{array}{l}\text { Whole body total } \\
\text { lean mass }(\mathrm{kg})\end{array}$ & $61.8 \pm 6.7$ & \\
\hline $\begin{array}{l}\text { Cross-sectional muscle } \\
\text { area radius } 66 \%\left(\mathrm{~cm}^{2}\right)\end{array}$ & $45.0 \pm 6.0$ & \\
\hline $\begin{array}{l}\text { Cross-sectional muscle } \\
\text { area tibia } 66 \%\left(\mathrm{~cm}^{2}\right)\end{array}$ & $82.6 \pm 11.4$ & \\
\hline \multicolumn{3}{|l|}{ Thyroid hormones } \\
\hline $\mathrm{TSH}(\mu \mathrm{U} / \mathrm{ml})$ & $1.6(1.2-2.1)$ & $0.3-4.2$ \\
\hline $\mathrm{FT}_{3}(\mathrm{pg} / \mathrm{dl})$ & $383 \pm 40$ & $250-440$ \\
\hline $\mathrm{FT}_{4}(\mathrm{ng} / \mathrm{dl})$ & $1.4 \pm 0.2$ & $0.9-1.7$ \\
\hline TBG (mg/dl) & $1.8 \pm 0.3$ & $1.2-2.3$ \\
\hline
\end{tabular}

$\mathrm{IQ}$, interquartile.

as standardized estimates of effect size $(\beta)$ with their respective S.D. All analyses were adjusted for age, height, and weight. Considering the multiple comparisons, significance levels for associations were set at $P$ values $\leq 0.001$. Statistical analyses were performed using Spotfire S+8.1 (Insightful, Seattle, WA, USA) and MedCalc (Mariakerke, Belgium).
Taking advantage of the family structure of the dataset, the polygenic program in SOLAR 4.0 (South-west Foundation for Biomedical Research, San Antonio, TX, USA) was used to estimate the genetic ( $\rho G)$ correlation between body composition and circulating thyroid hormone concentrations (27).

\section{Results}

\section{General characteristics and thyroid hormone status}

The general characteristics, parameters of body composition, and thyroid hormone concentrations of the study population are shown in Table 1 . Based on the inclusion criteria, all subjects are in good health and euthyroid.

Median levels of glucose are $85 \mathrm{mg} / \mathrm{dl}$ (interquartile range (IQR): 79-91), median insulin is $6.4 \mu \mathrm{U} / \mathrm{ml}$ (IQR: 4.5-9.0), and median calculated HOMA-IR is 1.64 (IQR: 0.92-1.93). Median leptin level is $4.1 \mu \mathrm{g} / \mathrm{l}$ (IQR: 2.5-6.8) and strongly related to whole body fat mass $(\beta=0.84, P<0.0001)$. Mean levels of IGF1 are $402 \pm 96 \mathrm{ng} / \mathrm{dl}$ and mean levels of IGFBP 3 $3800 \pm 445 \mathrm{ng} / \mathrm{ml}$. Descriptives for sex steroids were described earlier (24). TSH concentrations in smokers are lower $(9 \%, P=0.0008)$ compared with non-smokers.

\section{Thyroid hormone levels in relation to body composition}

Associations between thyroid hormones and body composition are shown in Table 2; Figs 1 and 2 . Associations for $\mathrm{TT}_{3}$ and $\mathrm{TT}_{4}$ are shown in the Supplementary Table, see section on supplementary data given at the end of this article. Overall, positive associations are observed between circulating thyroid hormone levels and weight, BMI, and fat mass. More

Table 2 Standardized estimates of mixed effects model describing the relationship between thyroid hormones (independent) and body composition (dependent). Data presented as standardized estimate \pm s.D. Results from mixed effects model to account for family structure and adjusted for age, height and weight, except models for weight (age, height), and BMI (age).

\begin{tabular}{|c|c|c|c|c|}
\hline & TSH $(\mu \mathrm{U} / \mathrm{l})$ & $\mathbf{F T}_{3}(\mathrm{pg} / \mathrm{dl})$ & $\mathrm{FT}_{4}(\mathrm{ng} / \mathrm{dl})$ & TBG (mg/dl) \\
\hline Weight $(\mathrm{kg})$ & $\begin{array}{l}-0.01 \pm 0.03 \\
P=0.9\end{array}$ & $\begin{array}{l}0.16 \pm 0.03 \\
P<0.0001\end{array}$ & $\begin{array}{l}-0.02 \pm 0.03 \\
P=0.6\end{array}$ & $\begin{array}{l}0.09 \pm 0.03 \\
P=0.004\end{array}$ \\
\hline BMI $\left(\mathrm{kg} / \mathrm{m}^{2}\right)$ & $\begin{array}{l}-0.01 \pm 0.03 \\
P=0.9\end{array}$ & $\begin{array}{l}0.18 \pm 0.03 \\
P<0.0001\end{array}$ & $\begin{array}{l}-0.03 \pm 0.03 \\
P=0.4\end{array}$ & $\begin{array}{l}0.09 \pm 0.03 \\
P=0.004\end{array}$ \\
\hline Whole body fat mass $(\mathrm{kg})$ & $\begin{array}{l}-0.01 \pm 0.02 \\
P=0.9\end{array}$ & $\begin{array}{l}0.04 \pm 0.02 \\
P=0.02\end{array}$ & $\begin{array}{l}0.06 \pm 0.02 \\
P=0.0006\end{array}$ & $\begin{array}{l}0.1 \pm 0.02 \\
P<0.0001\end{array}$ \\
\hline Trunk fat mass $(\mathrm{kg})$ & $\begin{array}{l}-0.01 \pm 0.02 \\
P=0.9\end{array}$ & $\begin{array}{l}0.03 \pm 0.02 \\
P=0.08\end{array}$ & $\begin{array}{l}0.04 \pm 0.02 \\
P=0.03\end{array}$ & $\begin{array}{l}0.08 \pm 0.02 \\
P<0.0001\end{array}$ \\
\hline Whole body lean mass $(\mathrm{kg})$ & $\begin{array}{l}-0.01 \pm 0.01 \\
P=0.6\end{array}$ & $\begin{array}{l}-0.02 \pm 0.02 \\
P=0.1\end{array}$ & $\begin{array}{l}-0.04 \pm 0.01 \\
P=0.004\end{array}$ & $\begin{array}{l}-0.1 \pm 0.01 \\
P<0.0001\end{array}$ \\
\hline CSMA radius $66 \%\left(\mathrm{~mm}^{2}\right)$ & $\begin{array}{l}0.01 \pm 0.03 \\
P=0.7\end{array}$ & $\begin{array}{l}0.02 \pm 0.03 \\
P=0.4\end{array}$ & $\begin{array}{l}-0.13 \pm 0.03 \\
P<0.0001\end{array}$ & $\begin{array}{l}-0.06 \pm 0.03 \\
P=0.03\end{array}$ \\
\hline CSMA tibia $66 \%\left(\mathrm{~mm}^{2}\right)$ & $\begin{array}{l}0.02 \pm 0.03 \\
P=0.6\end{array}$ & $\begin{array}{l}-0.09 \pm 0.03 \\
P=0.0006\end{array}$ & $\begin{array}{l}-0.02 \pm 0.03 \\
P=0.6\end{array}$ & $\begin{array}{l}-0.08 \pm 0.03 \\
P=0.003\end{array}$ \\
\hline
\end{tabular}

CSMA, cross sectional muscle area 

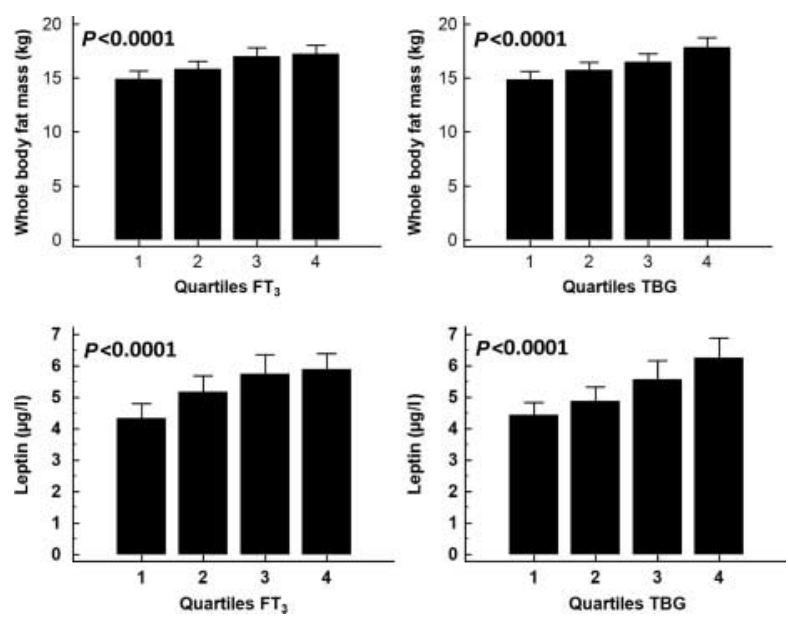

Figure 1 Whole body fat mass and leptin concentration according to quartiles of $\mathrm{FT}_{3}$ and TBG. A gradual positive association is observed with increasing quartiles of thyroid hormones.

specifically, we find positive associations between $\mathrm{T}_{3}$ and weight, BMI, and fat mass. $(\mathrm{F}) \mathrm{T}_{4}$ and $\mathrm{TBG}$ are also positively associated to fat mass but not to weight and BMI. As shown in Fig. 1, a gradual increase in fat mass is observed with ascending quartiles of thyroid hormones.

When associations with free or total thyroid hormones are additionally adjusted for TBG, $\mathrm{FT}_{3}$ remains significantly associated with both weight and BMI. Parameters of muscle mass (whole body lean mass and cross-sectional muscle area at the level of the radius and the tibia) are inversely associated with thyroid hormones (Table 2; Fig. 2; and Supplementary Table). The associations between $\mathrm{FT}_{4}$ and lean or fat mass remain significant when an additional adjustment for TBG is performed (data not shown). $\mathrm{rT}_{3}$ is also positively associated with fat mass $(\beta=0.06, P=0.0007)$ and inversely with lean mass $(\beta=-0.06, P<0.0001)$ (data not shown in Table 2). TSH is not associated with parameters of body composition in our euthyroid men (Table 2). The observed associations between thyroid hormone levels and body composition are not affected by smoking status (data not shown).

\section{Thyroid hormone levels in relation to leptin and parameters of glucose metabolism}

Table 3 summarizes associations between thyroid hormones and glucose, insulin, HOMA-IR, and leptin. Associations for $\mathrm{TT}_{3}$ and $\mathrm{TT}_{4}$ are shown in the Supplementary Table. Figure 1 shows the association between leptin and quartiles of thyroid hormone levels.

In agreement with the data for fat mass, serum leptin is positively associated with thyroid hormone levels and TBG. The ratio $\mathrm{FT}_{3} / \mathrm{FT}_{4}$ is also positively associated with leptin (unadjusted; $\beta=0.10, P=0.001$ ), as well as with whole body fat mass $(\beta=0.12, P=0.0006) . \mathrm{rT}_{3}$ is only borderline-significant associated with leptin $(\beta=0.07$, $P=0.003)$. The ratios $\mathrm{TT}_{3} / \mathrm{TT}_{4}$ and $\mathrm{TT}_{3} / \mathrm{rT}_{3}$, as reflections of peripheral thyroid hormone metabolism, are not significantly associated with leptin or fat mass in this study (data not shown).

A positive association between TSH and leptin is observed, but this association does not reach the predefined significance criterion. When adjusting for fat mass instead of weight, the observed associations between thyroid hormones and leptin are no longer significant (data not shown), except for the association with TSH $(P=0.001)$. Serum insulin and HOMA-IR are positively associated with (F) $\mathrm{T}_{3}$ and with TBG. However, after adjustment for fat mass instead of weight, these associations do not reach the significance criterion anymore (data not shown). When the associations with free thyroid hormones, presented in Table 3, are additionally adjusted for TBG, only TBG remains significantly associated with the metabolic parameters (data not shown).

\section{Differences between obese and non-obese subjects}

No BMI-threshold is observed considering the associations between body composition and thyroid hormones. Exclusion of obese subjects (BMI $>30$, $n=77$ ) from analyses does not change the observed associations significantly, indicative of a continuous association.

\section{Genetic correlations between indices of thyroid function and body composition}

Using the family structure of our data, genetic and environmental correlations between thyroid hormones and body composition were assessed using SOLAR. Shared genes are found to make up 7 and $8 \%$ of the genetic variation in TBG and fat and lean mass respectively $(P<0.005)$. No significant genetic correlation is observed between $(\mathrm{F}) \mathrm{T}_{3}$ or $(\mathrm{F}) \mathrm{T}_{4}$ and fat or lean mass (data not shown). Based on these findings we conclude that the associations between body composition and circulating thyroid hormones are mainly environmentally determined.
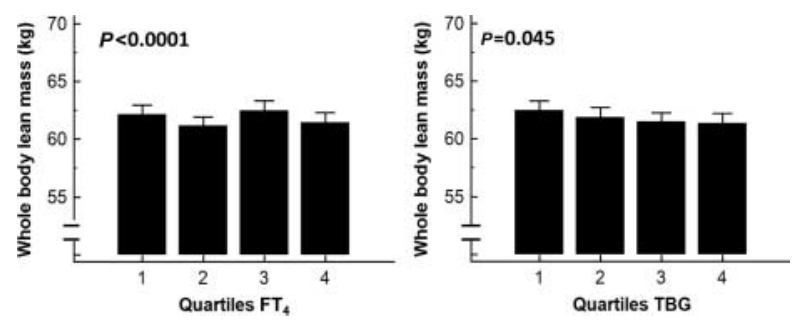

Figure 2 Whole body lean mass according to quartiles of $\mathrm{FT}_{4}$ and TBG. A gradual negative association is observed with increasing quartiles of thyroid hormones. 
Table 3 Standardized estimates of mixed effects model describing the relationship between thyroid hormones (independent) and parameters of glucose metabolism and leptin (dependent). Data presented as standardized estimate \pm S.D. Results from mixed effects model to account for family structure and adjusted for age, height, and weight.

\begin{tabular}{lllll}
\hline & TSH $(\mu \mathrm{U} / \mathrm{l})$ & $\mathrm{FT}_{\mathbf{3}}(\mathrm{pg} / \mathrm{dl})$ & $\mathbf{F T}_{\mathbf{4}}(\mathrm{ng} / \mathrm{dl})$ & TBG $(\mathrm{mg} / \mathrm{dl})$ \\
\hline Glucose $(\mathrm{mg} / \mathrm{dl})$ & $-0.05 \pm 0.03$ & $0.06 \pm 0.03$ & $-0.02 \pm 0.03$ & $0.06 \pm 0.03$ \\
& $P=0.1$ & $P=0.09$ & $P=0.6$ & $P=0.06$ \\
Insulin $(\mu \mathrm{U} / \mathrm{ml})$ & $0.04 \pm 0.03$ & $0.11 \pm 0.03$ & $-0.02 \pm 0.03$ & $0.12 \pm 0.03$ \\
& $P=0.1$ & $P=0.0001$ & $P=0.6$ & $P=0.0001$ \\
HOMA-IR & $0.03 \pm 0.03$ & $0.12 \pm 0.03$ & $-0.02 \pm 0.03$ & $0.12 \pm 0.03$ \\
& $P=0.3$ & $P=0.0001$ & $P=0.5$ & $P<0.0001$ \\
Leptin $(\mu \mathrm{g} / \mathrm{l})$ & $0.05 \pm 0.02$ & $0.09 \pm 0.02$ & $0.07 \pm 0.02$ & $0.11 \pm 0.02$ \\
& $P=0.03$ & $P=0.0001$ & $P=0.003$ & $P<0.0001$ \\
\hline
\end{tabular}

\section{Interrelation between thyroid hormones and sex steroids (total testosterone and $\left.E_{2}\right)$ and SHBG}

No associations are observed between total testosterone or $\mathrm{E}_{2}$, and thyroid hormone levels in a subgroup of the population $(n=677)$, except for a positive association between $\mathrm{FT}_{4}$ and total testosterone $(\beta=0.12$, $P=0.0002)$. SHBG is positively associated with TBG $(\beta=0.15, P=0.0001)$. Additional adjustment for total testosterone, total $\mathrm{E}_{2}$, or SHBG did not change the significance of the observed associations between thyroid hormone levels and body composition.

\section{Interrelation between thyroid hormones and the GH axis (IGF1 and IGFBP3)}

No associations between thyroid hormone levels and IGF 1 or IGFBP 3 are observed in a subgroup of the population $(n=677)$. Additional adjustment for IGF1 or IGFBP 3 marginally affected the associations between $\mathrm{FT}_{3}$ and fat mass and insulin (resistance), but other associations between thyroid hormone levels and body composition or metabolic parameters remained significant.

\section{Discussion}

This study, performed in a population of healthy euthyroid young men, demonstrates that body composition and metabolic parameters are associated with variation in thyroid hormone levels, mainly with TBG and with $\mathrm{FT}_{3}$. More explicitly, we observe strong positive associations between thyroid hormone levels and indices of adiposity, whereas negative associations are found with parameters of muscularity. TSH is not associated with either body composition or the assessed metabolic indices in these euthyroid young men.

Our findings are in agreement with Alevizaki et al. (4) and De Pergola et al. (28), who describe positive relations between $\mathrm{T}_{3}$ and BMI, both in men and women with normal BMI, as in obese women. However, other authors found no relation between $\mathrm{FT}_{3}$ and BMI
(8) or negative associations between $\mathrm{FT}_{4}$ and body weight $(8,11,29)$ or subcutaneous abdominal fat (4). Nevertheless, in most of the latter studies, no information was available on adiposity or muscularity, so the results are difficult to compare with results of this study which assessed muscle and fat mass separately.

The cross-sectional design of our study does not allow us to establish the direction of the observed associations. However, our results are suggestive for an effect of body composition on circulating thyroid hormone concentrations. We hypothesize that part of the effects of body fat on thyroid hormone concentrations can be explained through TBG. As TBG is regarded as a marker of nutritional status, it is expected to be higher in subjects with a higher fat mass. In line with this hypothesis, we observe a positive and gradual relation between TBG and weight, BMI, or fat mass. The observation of a shared genetic background for TBG, lean, and fat mass corroborates this hypothesis.

In addition, we demonstrate also associations of free thyroid hormone levels with body composition and metabolic parameters. As some of these associations remain significant after adjustment for TBG, this suggests additional effects of body composition on thyroid hormone concentrations, besides the effect on TBG. Leptin could be one of the mediators for these effects, as it can influence the thyroid hormone axis, both by central and peripheral mechanisms. At the hypothalamus, leptin has been found to stimulate TRH expression both directly in the paraventricular nucleus as well as indirectly via the nucleus arcuatus (16). Besides, TSH has also been found to stimulate leptin secretion by a direct effect on adipocytes, probably via TSH-receptors on the surface of adipocytes $(30,31)$. We assume that the positive association between leptin and TSH could be caused by this direct effect of TSH on leptin secretion by adipocytes. Also, a direct stimulatory effect of leptin on $\mathrm{T}_{4}$ release from the thyroid gland has been reported (32), besides regulating effects on central and peripheral (e.g. in fat mass) iodothyronine deiodinase activities and thus conversion of $\mathrm{T}_{4}$ to $\mathrm{T}_{3}$ (33). Indeed, in our young men, we observe a positive association between leptin or fat mass and the ratio $\mathrm{FT}_{3} / \mathrm{FT}_{4}$. Exclusion of the obese subjects (with BMI $>30$ ) does not 
change the observed associations. These associations between thyroid hormones and body composition are thus not driven by the obese subjects solely, because effects of a less favorable body composition are present across the normal weight range. In summary, we hypothesize that, in our study, the positive association between leptin and TSH might be due to direct effects of TSH on leptin secretion by adipocytes, while higher fat mass with the consequent higher leptin levels could influence free thyroid hormones. Nevertheless, given this complex regulation between leptin and several components of the thyroid hormone system, different effects may have outweighed each other and in any case conclusions on the causal mechanisms cannot be drawn from this cross-sectional study.

Although TSH is regarded as the most sensitive reflection of thyroid status to detect thyroid dysfunction, considering the thyroid hypothalamic feedback regulation, it is not associated with the parameters of body composition in our study. Nevertheless, a substantial body of literature describes a positive relation between TSH and body weight $(5,6,7,8,9)$, although others fail to confirm this relationship $(11,12,29,34)$. Possible explanations for the diverging results between these studies might be differences in studied populations with regard to smoking status (5), presence of obesity (15), gender differences $(6,7)$, and older age (9). The absence of associations between TSH and weight or fat mass in our population can probably be explained by three main reasons.

First, as we studied the influence of variations in thyroid function within the normal range, we excluded subjects with a history of thyroid disease, treatment with thyroid hormones, or with positive levels of thyroid autoantibodies from our analyses. In this group of 941 subjects, we observed no associations between TSH and levels of free or total thyroid hormones. However, in the subjects with positive thyroid autoimmunity, which were excluded from this study population, we did observe an inverse log-linear association between TSH and $\mathrm{FT}_{4}$ (data not shown). The absence of a $\mathrm{TSH}-\mathrm{T}_{4}$ relationship is thus compatible with the premise that we studied strictly euthyroid subjects, whereas associations with TSH in other studies can be caused by latent subclinical thyroid disease. Secondly, by using males within a particular age group without thyroid disease, we have isolated a subgroup with a rather narrow range of TSH, which might have impaired the power to detect associations between TSH and body composition. Finally, as the positive association between TSH and weight is merely observed in obese subjects (35), the rather narrow weight range and the fact that we studied mostly non-obese subjects in our study can be a third explanation.

In agreement with our observations for body composition, thyroid hormone concentrations are also associated with indices of IR in this study. Apart from the mutual association with body composition, there may also be a direct link between thyroid function and glucose metabolism. With regard to thyroid dysfunction, both hyper- and hypothyroidism have been reported to be associated with IR (17). This apparent paradox may result from the differential effects of thyroid hormones at the level of the liver (insulin antagonistic) and peripheral tissues (e.g. in muscles: insulin agonistic) (36). Our observations of positive associations between $\mathrm{T}_{3}$ and insulin (resistance) in euthyroid men are consistent with the results of Ortega et al. (37) and Bakker et al. (38) in euthyroid but obese Pima Indians and in lean euthyroid men and women respectively. Nevertheless, we have no arguments for direct effects of thyroid hormones on the glucose metabolism in our study, given the disappearance of associations after adjustment for fat mass rather than for weight.

Besides the positive associations between thyroid hormone concentrations and fat mass, significant inverse associations with lean mass and muscular mass are observed. $\mathrm{FT}_{4}$, TBG, $\mathrm{TT}_{3}$, and $\mathrm{TT}_{4}$ (Supplementary Table) are higher when lean body mass and muscle area are lower, in agreement with inverse associations between $\mathrm{T}_{3}$ and $\mathrm{T}_{4}$ and lean mass, physical performance scale, and muscle strength observed in healthy elderly men by Van den Beld et al. (21). These observations can be considered as complementary to our findings of positive associations with higher fat mass. Moreover, unfavorable effects of higher circulating thyroid hormones, even within the normal range, in agreement with our observations for bone mass (23), on skeletal muscle are also possible, given that muscle weakness is a common and well-known complication of thyrotoxicosis. Even in subclinical hyperthyroidism, muscular strength and cross-sectional area are reduced and improve after treatment (20), although the exact molecular mechanism of muscle weakness in hyperthyroidism is incompletely understood (39).

Notwithstanding existing associations between hormones of both gonadal and somatotropic axes and body composition (40), these hormones did not seem to modulate the observed associations between thyroid hormone levels and body composition or metabolic parameters in our population.

The main limitation of this study is its cross-sectional design which does not allow establishing the direction of associations. Another limitation is that free thyroid hormones in our study are determined by direct immunoassays. The analytical performance of these immunoassays has been questioned and biases have been reported, e.g. secondary to changes in binding proteins (41). We cannot therefore exclude that the measured levels of free thyroid hormones in our study are not entirely independent from TBG. Nevertheless, associations between free thyroid hormones and body composition remained significant after adjustment for TBG. Furthermore, the immunoassay used in this study has been shown to have an acceptable quality of 
performance when measuring samples from non-diseased individuals (42).

This study also has several strengths. First, as we determined thyroid autoantibodies, we were able to exclude persons with thyroid autoimmunity. Therefore, we can be confident that this study in young men reliably represents euthyroid subjects. Secondly, we obtained an extensive characterization of body composition, whereas most prior studies assessed body weight without differentiation between lean and fat mass.

In summary, in this population of young men with well-characterized euthyroidism, a less favorable body composition with higher fat- and lower muscle mass and accompanying higher leptin levels, as well as lower insulin sensitivity, are positively associated with serum TBG and thyroid hormone levels.

\section{Supplementary data}

This is linked to the online version of the paper at http://dx.doi.org/10. 1530/EJE-12-0447.

\section{Declaration of interest}

The authors declare that there is no conflict of interest that could be perceived as prejudicing the impartiality of the research reported.

\section{Funding}

This work was supported by a grant from the Fund for Scientific Research - Flanders (FWO-Vlaanderen grant \#G.0662.08). $\mathrm{Y}$ Taes is holder of a post-doctoral fellowship of the Research Foundation - Flanders (FWO).

\section{Acknowledgements}

The authors are grateful to Kaatje Toye, Kathelyne Mertens, Magda Becqué, and Eric Vandersypt for their excellent technical assistance. They also thank all the volunteers who participated as study subjects.

\section{References}

1 Corbetta S, Englaro P, Giambona S, Persani L, Blum WF \& Beck-Peccoz P. Lack of effects of circulating thyroid hormone levels on serum leptin concentrations. European Journal of Endocrinology 1997137 659-663. (doi:10.1530/eje.0.1370659)

2 Hoogwerf BJ \& Nuttall FQ. Long-term weight regulation in treated hyperthyroid and hypothyroid subjects. American Journal of Medicine $1984 \quad 76$ 963-970. (doi:10.1016/0002-9343(84) 90842-8)

3 Dale J, Daykin J, Holder R, Sheppard MC \& Franklyn JA. Weight gain following treatment of hyperthyroidism. Clinical Endocrinology 200155 233-239. (doi:10.1046/j.1365-2265.2001.01329.x)

4 Alevizaki M, Saltiki K, Voidonikola P, Mantzou E, Papamichael C \& Stamatelopoulos K. Free thyroxine is an independent predictor of subcutaneous fat in euthyroid individuals. European Journal of Endocrinology 2009161 459-465. (doi:10.1530/EJE-09-0441)

5 Asvold BO, Bjoro T \& Vatten LJ. Association of serum TSH with high body mass differs between smokers and never-smokers. Journal of Clinical Endocrinology and Metabolism 2009 94 5023-5027. (doi:10.1210/jc.2009-1180)

6 Dvorakova M, Hill M, Cerovska J, Pobisova Z, Bilek R, Hoskovcova P, Zamrazil V \& Hainer V. Relationship between pituitary-thyroid axis hormones and anthropometric parameters in Czech adult population. Physiological Research 2008 57 (Suppl 1) S127-S134.

7 Fox CS, Pencina MJ, D’Agostino RB, Murabito JM, Seely EW, Pearce EN \& Vasan RS. Relations of thyroid function to body weight: cross-sectional and longitudinal observations in a community-based sample. Archives of Internal Medicine 2008 168 587-592. (doi:10.1001/archinte.168.6.587)

8 Knudsen N, Laurberg P, Rasmussen LB, Bulow I, Perrild H, Ovesen L \& Jorgensen T. Small differences in thyroid function may be important for body mass index and the occurrence of obesity in the population. Journal of Clinical Endocrinology and Metabolism 200590 4019-4024. (doi:10.1210/jc.2004-2225)

9 Nyrnes A, Jorde R \& Sundsfjord J. Serum TSH is positively associated with BMI. International Journal of Obesity 200630 100-105. (doi:10.1038/sj.ijo.0803112)

10 Diez JJ \& Iglesias P. Relationship between thyrotropin and body mass index in euthyroid subjects. Experimental and Clinical Endocrinology \& Diabetes 2011119 144-150. (doi:10.1055/s0030-1265133)

11 Makepeace AE, Bremner AP, O'Leary P, Leedman PJ, Feddema P, Michelangeli $V$ \& Walsh JP. Significant inverse relationship between serum free $\mathrm{T}_{4}$ concentration and body mass index in euthyroid subjects: differences between smokers and nonsmokers. Clinical Endocrinology 200869 648-652. (doi:10.1111/j.13652265.2008.03239.x)

12 Manji N, Boelaert K, Sheppard MC, Holder RL, Gough SC \& Franklyn JA. Lack of association between serum TSH or free $\mathrm{T}_{4}$ and body mass index in euthyroid subjects. Clinical Endocrinology 200664 125-128. (doi:10.1111/j.1365-2265.2006.02433.x)

13 Reinehr T. Obesity and thyroid function. Molecular and Cellular Endocrinology 2010316 165-171. (doi:10.1016/j.mce.2009. 06.005)

14 Svare A, Nilsen TI, Bjoro T, Asvold BO \& Langhammer A. Serum TSH related to measures of body mass: longitudinal data from the HUNT Study, Norway. Clinical Endocrinology 2011 74 769-775. (doi:10.1111/j.1365-2265.2011.04009.x)

15 Iacobellis G, Ribaudo MC, Zappaterreno A, Iannucci CV \& Leonetti F. Relationship of thyroid function with body mass index, leptin, insulin sensitivity and adiponectin in euthyroid obese women. Clinical Endocrinology $200562 \quad 487-491$. (doi:10.1111/j.1365-2265.2005.02247.x)

16 Ghamari-Langroudi M, Vella KR, Srisai D, Sugrue ML, Hollenberg AN \& Cone RD. Regulation of thyrotropin-releasing hormone-expressing neurons in paraventricular nucleus of the hypothalamus by signals of adiposity. Molecular Endocrinology 201024 2366-2381. (doi:10.1210/me.2010-0203)

17 Lambadiari V, Mitrou P, Maratou E, Raptis AE, Tountas N, Raptis SA \& Dimitriadis G. Thyroid hormones are positively associated with insulin resistance early in the development of type 2 diabetes. Endocrine 201139 28-32. (doi:10.1007/s12020010-9408-3)

18 Dimitriadis G, Baker B, Marsh H, Mandarino L, Rizza R, Bergman R, Haymond M \& Gerich J. Effect of thyroid hormone excess on action, secretion, and metabolism of insulin in humans. American Journal of Physiology 1985248 E593-E601.

19 Dubois S, Abraham P, Rohmer V, Rodien P, Audran M, Dumas JF \& Ritz P. Thyroxine therapy in euthyroid patients does not affect body composition or muscular function. Thyroid $2008 \mathbf{1 8}$ 13-19. (doi:10.1089/thy.2007.0037)

20 Brennan MD, Powell C, Kaufman KR, Sun PC, Bahn RS \& Nair KS. The impact of overt and subclinical hyperthyroidism on skeletal muscle. Thyroid 200616 375-380. (doi:10.1089/thy. 2006.16.375)

21 van den Beld AW, Visser TJ, Feelders RA, Grobbee DE \& Lamberts SW. Thyroid hormone concentrations, disease, physical function, and mortality in elderly men. Journal of Clinical Endocrinology and Metabolism 200590 6403-6409. (doi:10.1210/jc.2005-0872)

22 Murphy E, Gluer CC, Reid DM, Felsenberg D, Roux C, Eastell R \& Williams GR. Thyroid function within the upper normal range is 
associated with reduced bone mineral density and an increased risk of nonvertebral fractures in healthy euthyroid postmenopausal women. Journal of Clinical Endocrinology and Metabolism 201095 3173-3181. (doi:10.1210/jc.2009-2630)

23 Roef G, Lapauw B, Goemaere S, Zmierczak H, Fiers T, Kaufman JM \& Taes Y. Thyroid hormone status within the physiological range affects bone mass and density in healthy men at the age of peak bone mass. European Journal of Endocrinology $2011 \mathbf{1 6 4}$ 1027-1034. (doi:10.1530/EJE-10-1113)

24 Lapauw BM, Taes Y, Bogaert V, Vanbillemont G, Goemaere S, Zmierczak HG, De Bacquer D \& Kaufman JM. Serum estradiol is associated with volumetric BMD and modulates the impact of physical activity on bone size at the age of peak bone mass: a study in healthy male siblings. Journal of Bone and Mineral Research 2009 24 1075-1085. (doi:10.1359/jbmr.081260)

25 Taes Y, Lapauw B, Vanbillemont G, Bogaert V, De Bacquer D, Goemaere S, Zmierczak H \& Kaufman JM. Early smoking is associated with peak bone mass and prevalent fractures in young, healthy men. Journal of Bone and Mineral Research 201025 379-387. (doi:10.1359/jbmr.090809)

26 Matthews DR, Hosker JP, Rudenski AS, Naylor BA, Treacher DF \& Turner RC. Homeostasis model assessment: insulin resistance and $\beta$-cell function from fasting plasma glucose and insulin concentrations in man. Diabetologia 198528 412-419. (doi:10.1007/ BF00280883)

27 Almasy L \& Blangero J. Multipoint quantitative-trait linkage analysis in general pedigrees. American Journal of Human Genetics 199862 1198-1211. (doi:10.1086/301844)

28 De Pergola G, Ciampolillo A, Paolotti S, Trerotoli P \& Giorgino R. Free triiodothyronine and thyroid stimulating hormone are directly associated with waist circumference, independently of insulin resistance, metabolic parameters and blood pressure in overweight and obese women. Clinical Endocrinology 200767 265-269. (doi:10.1111/j.1365-2265.2007.02874.x)

29 Shon HS, Jung ED, Kim SH \& Lee JH. Free $\mathrm{T}_{4}$ is negatively correlated with body mass index in euthyroid women. Korean Journal of Internal Medicine 200823 53-57. (doi:10.3904/kjim. 2008.23.2.53)

30 Santini F, Galli G, Maffei M, Fierabracci P, Pelosini C, Marsili A, Giannetti M, Castagna MG, Checchi S, Molinaro E, Piaggi P, Pacini F, Elisei R, Vitti P \& Pinchera A. Acute exogenous TSH administration stimulates leptin secretion in vivo. European Journal of Endocrinology 2010163 63-67. (doi:10.1530/EJE10-0138)

31 Menendez C, Baldelli R, Camina JP, Escudero B, Peino R, Dieguez C \& Casanueva FF. TSH stimulates leptin secretion by a direct effect on adipocytes. Journal of Endocrinology 2003176 7-12. (doi:10.1677/joe.0.1760007)

32 Rosenbaum M, Goldsmith R, Bloomfield D, Magnano A, Weimer L, Heymsfield S, Gallagher D, Mayer L, Murphy E \& Leibel RL. Low-dose leptin reverses skeletal muscle, autonomic, and neuroendocrine adaptations to maintenance of reduced weight. Journal of Clinical Investigation 2005115 3579-3586. (doi:10.1172/JCI25977)

33 Araujo RL \& Carvalho DP. Bioenergetic impact of tissue-specific regulation of iodothyronine deiodinases during nutritional imbalance. Journal of Bioenergetics and Biomembranes 201143 59-65. (doi:10.1007/s10863-011-9327-x)

34 Michalaki MA, Vagenakis AG, Leonardou AS, Argentou MN, Habeos IG, Makri MG, Psyrogiannis AI, Kalfarentzos FE \& Kyriazopoulou VE. Thyroid function in humans with morbid obesity. Thyroid 200616 73-78. (doi:10.1089/thy.2006.16.73)

35 Rotondi M, Leporati P, La Manna A, Pirali B, Mondello T, Fonte R, Magri F \& Chiovato L. Raised serum TSH levels in patients with morbid obesity: is it enough to diagnose subclinical hypothyroidism? European Journal of Endocrinology $2009 \mathbf{1 6 0}$ 403-408. (doi:10.1530/EJE-08-0734)

36 Brenta G. Why can insulin resistance be a natural consequence of thyroid dysfunction? Journal of Thyroid Research 20112011 152850. (doi:10.4061/2011/152850)

37 Ortega E, Koska J, Pannacciulli N, Bunt JC \& Krakoff J. Free triiodothyronine plasma concentrations are positively associated with insulin secretion in euthyroid individuals. European Journal of Endocrinology 2008158 217-221. (doi:10.1530/EJE-07-0592)

38 Bakker SJ, ter Maaten JC, Popp-Snijders C, Heine RJ \& Gans RO. Triiodothyronine: a link between the insulin resistance syndrome and blood pressure? Journal of Hypertension 199917 1725-1730. (doi:10.1097/00004872-199917120-00009)

39 Olson BR, Klein I, Benner R, Burdett R, Trzepacz P \& Levey GS. Hyperthyroid myopathy and the response to treatment. Thyroid 19911 137-141. (doi:10.1089/thy.1991.1.137)

40 Vanbillemont G, Lapauw B, De Naeyer H, Roef G, Kaufman JM \& Taes YE. Sex hormone-binding globulin at the crossroad of body composition, somatotropic axis and insulin/glucose homeostasis in young healthy men. Clinical Endocrinology 201276 111-118. (doi:10.1111/j.1365-2265.2011.04155.x)

41 Yue B, Rockwood AL, Sandrock T, La'ulu SL, Kushnir MM \& Meikle AW. Free thyroid hormones in serum by direct equilibrium dialysis and online solid-phase extraction - liquid chromatography/ tandem mass spectrometry. Clinical Chemistry 200854 642-651. (doi:10.1373/clinchem.2007.098293)

42 Thienpont LM, Van Uytfanghe K, Beastall G, Faix JD, Ieiri T, Miller WG, Nelson JC, Ronin C, Ross HA, Thijssen JH \& Toussaint B. Report of the IFCC Working Group for Standardization of Thyroid Function Tests; part 2: free thyroxine and free triiodothyronine. Clinical Chemistry $2010 \quad \mathbf{5 6}$ 912-920. (doi:10.1373/clinchem.2009.140194)

Received 22 May 2012

Revised version received 22 August 2012

Accepted 6 September 2012 